\title{
O PRINCÍPIO DA VEDAÇÃO AO RETROCESSO NA REFORMA DA PREVIDÊNCIA NO BRASIL
}

\author{
Ana Débora Rocha Sales ${ }^{1}$ \\ Alexandre Antonio Bruno da Silva ${ }^{2}$ \\ Marcella Mourão de Brito ${ }^{3}$
}

\begin{abstract}
Resumo
A reforma da previdência provocou um retrocesso frente as mudanças normativas do direito previdenciário provocadas pela Emenda Constitucional $n^{\circ} 103 / 2019$. O objetivo é analisar o princípio da reserva do possível, que age como uma limitação aos direitos sociais, levando em consideração os recursos disponíveis pelo Estado. A metodologia foi o dedutivo de cunho bibliográfico, com materiais teóricos, bem como documentos normativos. Concluímos que a atual reforma conduziu a redução dos direitos já positivados o que torna claro o desrespeito ao princípio da vedação ao retrocesso.
\end{abstract}

Palavras-chave: Constituição Federal; Direitos Fundamentais; Vedação; Retrocesso Social; Reforma da Previdência

\section{THE PRINCIPLE OF THE BACKREST PROOF IN THE REFORM OF PENSION IN} BRAZIL

\begin{abstract}
The social security reform caused a setback in face of the normative changes in social security law caused by Constitutional Amendment No. 103/2019. The objective is to analyze the principle of the reservation of the possible, which acts as a limitation on social rights, taking into account the resources available by the State. The methodology was bibliographic deductive, with theoretical materials as well as normative documents. We conclude that the current reform has led to a reduction in the rights that have already been affirmed, which makes clear the disrespect for the principle of prohibition of retrogression.

Keywords: Federal Constitution; Fundamental Rights; Seal; Social Regression; Social Security Reform
\end{abstract}

\section{INTRODUÇÃO}

\footnotetext{
${ }^{1}$ Doutoranda em Ciências Jurídicas pela Universidade del Museo Social Argentino- UMSA (2020- dias atuais). Mestranda em Direito pelo Centro Universitário Christus- UNICHRISTUS (2020- dias atuais), com bolsa parcial da CAPES. Pesquisadora na linha de Pesquisa de Epistemologia, Inteligência Artificial e Decisão Judicial do NUPID. Especialista em Direito Previdenciário pelo Centro Educacional Damásio de Jesus. Professora Voluntária na Universidade Estadual Vale do Acaraú- UVA. (anadeboraadv@ hotmail.com)

${ }^{2}$ Pós-Doutor pela Universidade de Sevilha. Doutor em Direito pela Pontifícia Universidade Católica de São Paulo (PUC/SP). Doutorando em Ciência Política, pela Universidade Estadual do Ceará (UECE). Mestre em Direito pela UFC/CE. Mestre em Informática pela PUC/RJ. Professor do Programa de Pós-Graduação Stricto Sensu do Centro Universitário Christus (UNICHRISTUS). Professor Adjunto da Universidade Estadual do Ceará (UECE). Auditor-Fiscal do Trabalho. (alexandre_bruno@terra.com.br)

${ }^{3}$ Doutoranda em Direito Constitucional pela Universidade de Fortaleza (UNIFOR). Mestre em Processo e Direito ao Desenvolvimento pelo Centro Universitário Christus (UNICHRISTUS). Mediadora Judicial com certificação emitida pelo CNJ. Professora Universitária do Centro Universitário UNIFAMETRO. Especialista em Mediaçã0 e Gestão de Conflitos pela UNIFOR. (marcellamouraob@gmail.com)
} 
A Constituição Federal de 1988 instituiu o Estado Social Democrático de Direito, em que delegou ao poder público a responsabilidade de garantir a todos os cidadãos brasileiros um conjunto de direitos que possibilite a construção de uma sociedade justa e igualitária. Em função disso, o Estado ganhou um papel fundamental na realização da justiça social, no processo de eliminação das desigualdades e na prevenção aos riscos sociais.

A Carta Magna evidencia em seu título II os direitos e garantias fundamentais, subdivididos em três categorias: os direitos individuais, direitos sociais e direitos difusos. Os direitos fundamentais são um conjunto de prerrogativas e garantias que os indivíduos conquistaram ao longo da história, que tem objetivo limitar a atuação do Estado frente as liberdades individuais. Concomitantemente, buscam instituir a progressiva melhoria na qualidade de vida das pessoas, sendo exigido a prestação positiva dos serviços essenciais à vida como: saúde, educação, segurança, lazer e previdência social.

Os direitos fundamentais, na Constituição Federal de 1988, estão resguardados pelo princípio da vedação ao retrocesso. Isso significa que o Estado brasileiro não pode regredir nos avanços obtidos na área social. Esse princípio se encontra de forma implícita na constituição brasileira resultante do sistema jurídico-constitucional, tendo como fundamento a limitação do legislador infraconstitucional em alterar de maneira a regredir, reduzir ou eliminar direitos já alcançados pela sociedade.

No âmbito dos direitos sociais expressos, está o direito à previdência social, contido no art. $6^{\circ}$ da constituição brasileira. De acordo com a intelecção do referido artigo, o regime de previdência brasileira só será constitucional se houver a cobertura dos eventos de doença, invalidez, morte, idade avançada, maternidade, desemprego involuntário e garantindo aos dependentes do segurado auxílio reclusão e pensão por morte. Ou seja, a constituição proíbe que haja uma proteção deficiente, que não seja capaz de assegurar plenamente às pessoas das eventualidades acima citadas.

Tendo em vista que a previdência social é um direito previsto constitucionalmente e, dessa forma, protegido pelo princípio da proibição ao retrocesso, o presente estudo tem como principal objetivo analisar as mudanças trazidas pela emenda constitucional $n^{\circ} 103$, de novembro de 2019, conhecida como Reforma da Previdência Social Brasileira. Portanto, 
pretende-se perquirir acerca da seguinte questão: A reforma da previdência viola o princípio constitucional de proibição ao retrocesso social?

Um outro instrumento utilizado nesta investigação é o efeito cliquet, que tem como principal expoente o constitucionalista português Canotilho (2003). Esse princípio está ligado à referências que os alpinistas fazem sobre impossibilidade de retroceder, em um determinado ponto de sua subida, tendo como única opção prosseguir com a escalada. Assim, por se tratar de direito previdenciário, que vem em constante progresso nas normas jurídicas do país, chegando a um nível de concretização e efetividade, que não é permitido retroceder, o que reduziria a capacidade da população em manter sua condição de vida alcançada mediante a evolução dos direitos.

Vale ressaltar que a previdência social é um direito prestacional, que demanda do Estado recursos financeiros necessários ao cumprimento da lei. Por esse motivo, aborda-se o Princípio da Reserva do Possível, que age como um condicionante à prestação de serviços, quando esses dependem diretamente dos recursos financeiros e orçamentários do Estado. Neste aspecto, a intenção é verificar até que ponto a reforma da previdência se justifica pela incapacidade do país em prover capital para a manutenção das normas vigentes.

A metodologia empregada neste artigo é de caráter bibliográfico, já que foram utilizadas referências disponíveis em artigos e livros, bem como na Constituição Federal de 1988 e na legislação referente ao direito previdenciário para o embasamento teórico deste estudo.

Este trabalho se subdivide em três sessões. A primeira diz respeito aos direitos fundamentais e o princípio da vedação ao retrocesso social, em que verificar-se-á o aporte legal que sustenta a necessidade do referido princípio para a efetivação do Estado Democrático de Direito. A posteriori, a discussão versará sobre o princípio da reserva do possível no âmbito do direito previdenciário. Por fim, serão analisadas as principais mudanças pautadas pela reforma da previdência, traçando comparações entre as normas revogadas e o novo regulamento da previdência social, frisando os efeitos da emenda $n^{\circ}$ 103/19 na concessão e no cálculo dos benefícios.

\section{OS DIREITOS FUNDAMENTAIS E O PRINCíPIO DA VEDAÇÃo AO RETROCESSO SOCIAL}


As constituições que surgiram depois da Segunda Guerra Mundial, expressam, em alguma medida, a legitimidade dos direitos do homem e os instrumentos para sua efetivação, uma tentativa de impedir a reincidência das atrocidades cometidas no referido conflito. Na Constituição Federal de 1988, os direitos humanos se positivam com a forma de Direitos Fundamentais. De acordo com Andrade (2020, p. 7) "uma vez elencado como direito fundamental, assumirá posição de extrema importância dentro do ordenamento jurídico em razão do seu status". Essa importância se dá, principalmente, pelo fato de se tratar da proteção do ser humano.

Os direitos fundamentais passaram a se manifestar na ordem jurídica seguindo a classificação em três gerações sucessivas, em que cada uma compreende a um dos ideais da Revolução Francesa: a liberdade, a igualdade e a fraternidade.

A primeira geração se refere aos direitos negativos, onde o Estado se abstém em favor dos direitos individuais. Os direitos dessa geração são relacionados à liberdade, uma vez que, impedem a atuação do Estado na vida pessoal da população. No conjunto desses direitos ainda encontramos os direitos de ir e vir, de crença, de associação e de livre processo.

A segunda geração dos direitos fundamentais consagra os direitos sociais, e se diferencia da geração anterior pelo seu caráter positivo. Nesse sentido, onde o Estado é impelido a agir na concessão de serviços essenciais à vida humana. Esses direitos remontam ao início do século XX, em que se concebe a ideia de bem-estar social, reconhecendo-se a necessidade de políticas públicas que atuem em favor da igualdade social. É nesse contexto que se encontra o direito previdenciário, objeto do presente estudo.

Por fim, os direitos de terceira geração são aqueles que se referem a toda sociedade, os quais preconizam o terceiro elemento do lema da Revolução francesa, a saber, a fraternidade. Bobbio (2004) descreve como sendo direito a solidariedade, a paz, ao meio ambiente ecologicamente equilibrado, a comunicação e ao desenvolvimento.

A divisão dos direitos fundamentais em gerações tem como principal objetivo a compreensão do processo de conquista e de positivação nas normas jurídicas, tento em vista que eles não possuem hierarquia e podem se apresentar em diferente ordem em cada Estado. Deve-se destacar que existem outras dimensões que não serão abordadas no presente trabalho. 
Nesse entendimento, parte da doutrina critica a utilização do termo gerações, pois passa a ideia de evolução, em que surgimento de uma substitui a anterior, o que não corresponde à realidade. Por isso, o termo considerado mais adequado por essa parte da doutrina é dimensões, pois transmite o entendimento de complementariedade de uma em relação a outra, sendo possível agir conjuntamente. (VIEIRA, 2015).

Embora haja divergência acerca da terminologia, os direitos fundamentais, segundo Bobbio (2004), são divididos em dois blocos distintos. O primeiro deles diz respeito aos dos direitos que impedem a atuação do estado e o segundo, por sua vez, aos que exigem a atuação dele. Essa divisão fica clara nos direitos de primeira e segunda geração, já os direitos de terceira geração podem conjugar tanto os direitos negativos como os positivos.

Os direitos fundamentais são expressos na Constituição Federal de 1988, no título II, nomeado como "Dos Direitos e Garantias Fundamentais". O rol dos direitos fundamentais no constitucionalismo pátrio é reconhecido como cláusula pétrea, em que "não será objeto de deliberação a proposta de emenda tendente a abolir” (BRASIL, 1988, p. 54) Segundo a concepção de Sarlet (2016) esse dispositivo constitucional dar margem a duas interpretações não opostas e complementares:

\footnotetext{
não apenas as alterações que objetivam a supressão dos princípios e direitos guindados à condição de "cláusula pétrea", mas também as que revelam uma tendência à sua supressão se encontram vedadas; b) os projetos de emenda que atentam contra esses mandamentos sequer poderão ser apreciados e votados pelo Congresso, de tal sorte que mesmo antes de sua promulgação se viabiliza o controle jurisdicional de sua constitucionalidade. (SARLET, 2016, p.1)
}

As cláusulas pétreas não objetivam a proteção dos dispositivos constitucionais em si, diz Sarlet (2016), pois estes podem ser alvo de modificações ou desenvolvimentos. O que realmente é preservada é a sua essência, a identidade da norma, isto é, seus princípios. Neste sentido, é possível concluir que as cláusulas pétreas proíbem o esvaziamento de certos princípios constitucionais.

Para Canotilho (2003), os direitos fundamentais devem ser dotados de garantias e estabilidade em relação as conquistas já alcançadas pela sociedade em relação ao legislador. Os direitos fundamentais são direitos subjetivos de natureza negativa. Ou seja, o Estado não pode suprimi-los, principalmente os direitos sociais, quando eles já estão positivados, possuem estabilidade no ordenamento jurídico. Portanto, o legislador infraconstitucional não pode vir a reduzir, reprimir ou retroceder esses direitos. 
Nesse contexto, Canotilho (2003) desenvolve a teoria do efeito cliquet, em que limita a atuação do Estado que se ver obrigado a sempre pensar em uma política pública que evolua o bem-estar da população e não haja retrocesso. A origem do princípio da vedação ao retrocesso se deu na Alemanha, por volta do ano de 1970. Nesse período, o país passava por uma severa crise econômica. Em razão disso, cogitava a possibilidade de reduzir ou extinguir alguns direitos exercidos pela população, o que gerou intensa discursão sobre a legitimidade das alterações nos benefícios sociais.

O embate se intensificou entre os favoráveis e os contrários ao desmonte dos benefícios sociais, sobretudo porque, na Lei Fundamental de Bonn não previa expressamente nenhum direito fundamental. O desenvolvimento do princípio da proibição ao retrocesso se constituiu como uma tentativa de proteger o retrocesso na área social. (NOVAIS, 2010).

Nessa linha de raciocínio, Canotilho disserta:

A "proibição de retrocesso social" nada pode fazer contra as recessões e crises
econômicas (reversibilidade fáctica), mas o princípio em análise limita a
reversibilidade dos direitos adquiridos (ex.: segurança social, subsídio de
desemprego, prestações de saúde), em clara violação do princípio da proteçãa da
confiança e da segurança dos cidadãos no âmbito econômico, social e cultural, e do
núcleo essencial da existência mínima, inerente ao respeito pela dignidade da pessoa
humana. (CANOTILHO, 2003, p. 338-339)

$\mathrm{Na}$ perspectiva de Canotilho (2003), a vedação ao retrocesso se constitui como guardião dos direitos pela sociedade conquistados, mesmo em face às instabilidades econômicas. Assim, imprescritível a sua observância, pois, caso contrário, seria flagrante a transgressão ao princípio da Dignidade da Pessoa Humana, o qual se relaciona intimamente com a proibição ao retrocesso social.

No sentindo mais amplo Ingo W. Sarlet define esse princípio como:

Toda e qualquer forma de proteção de direitos fundamentais em face de medidas do poder público, com destaque para o legislador e o administrador, que tenham por escopo a supressão ou mesmo restrição de direitos fundamentais (sejam eles sociais, ou não) $(2009$, p.131)

Embora o princípio não seja taxativo, na Constituição Federal de 1988, sua validade verifica-se quando analisados o $\$ 2^{\circ}$ do artigo $5^{\circ}$, que preveem a abrangência tanto dos princípios expressos da constituição quanto dos que dela decorrerem.

A doutrina afirma que a vedação ao retrocesso tem base legal extraído das seguintes normas constitucionais: O princípio do Estado Democrático de Direito, em que decorre o 
princípio da segurança jurídica, que preserva a estabilidade das relações jurídicas, impedindo que leis novas retirem direitos adquiridos por meio de lei antiga. $\mathrm{O}$ princípio da dignidade da pessoa humana, o qual prevê a atuação do Estado na construção de uma sociedade justa e igualitária, mediante a consolidação de políticas públicas. O princípio da máxima eficácia e efetividade, que estabelece a abrangência e a potencialização dos direitos fundamentais, que também otimiza a eficácia e efetividade do direito à segurança jurídica, exigindo o pleno desenvolvimento dos direitos fundamentais em detrimento às medidas de caráter retrocessivo (INGO SARLET, 2004) ${ }^{4}$

Nesse aspecto, o estudo do princípio da vedação ao retrocesso questiona se há possibilidade de o legislador restringir determinada norma, seja por emenda à constituição ou por reforma na esfera legislativa, ou ainda, revogar dispositivo regulador de norma constitucional direcionada à proteção dos direitos sociais.

Assim, o Direito Previdenciário, objeto do presente estudo, está contido nos Direitos Sociais, que por sua vez compõe a segunda geração descrita na Constituição Brasileira de 1988, por isso, se caracteriza como direito prestacional, em que o Estado é incumbido de sua efetivação.

Pode-se perceber que a doutrina, ainda que de uma forma tímida, reconhece que há previsão do princípio da proibição ao retrocesso em matéria previdenciária, não ocorrendo diferente no que concerne à jurisprudência pátria.

O primeiro julgamento da suprema corte que houve a manifestação do princípio da vedação ao retrocesso social ocorreu na Ação Direta de Inconstitucionalidade ${ }^{\circ} 2065$ DF. A ação foi apresentada pelos partidos que seguem: PT (partido dos trabalhadores) e PDT (Partido Democrático Trabalhista). O requerimento era a impugnação no art. 17 da Lei Provisória $n^{\circ}$ 1911-10/99, que extinguia o Conselho Nacional de Seguridade Social e os Conselhos Estaduais e Municipais de previdência, assegurados pelo $6^{\circ}$ e $7^{\circ}$ da lei 8.212/91 e os artigos $7^{\circ}$ e $8^{\circ}$ da lei 8.213/91. E por voto vencido do então ministro Sepúlveda Pertence,

\footnotetext{
${ }^{4}$ Sarlet, na tentativa de aprofundar o estudo acerca do tema, ressalta a íntima relação entre o princípio da dignidade da pessoa humana com a segurança jurídica. Pois, segundo ele, um verdadeiro Estado de Direito é também um Estado de segurança jurídica. "de tal sorte que a segurança jurídica passou a ter status de subprincípio fundamental e estruturante do Estado de direito" (INGO SARLET, 2004, p. 436). O princípio da Segurança jurídica é considerado incluso nos Direitos e garantias Fundamentais, da Carta Magna do Brasil, pois decorre do inciso XXXVI, do artigo $5^{\circ}$, onde afirma que "a lei não prejudicará o direito adquirido, o ato jurídico perfeito e a coisa julgada"
} 
houve o reconhecimento de inconstitucionalidade, pois o referido artigo violava expressamente com o princípio da vedação ao retrocesso. (ZUBA, 2011, p.121)

Embora não haja um regimento que defina claramente o alcance da proibição ao retrocesso, no caso concreto, o Supremo Tribunal Federal tende a reconhecer sua aplicabilidade. Mas nem sempre esse princípio deu conta de impedir as reformas que modificaram as normas do direito previdenciário ao longo dos anos. Um dos argumentos invocados pelos defensores é o grande déficit nos recursos que financiam a previdência. Esse motivo é duramente rebatido por grande parte da doutrina, tendo em vista que é prática comum a desvinculação dos recursos da previdência para outras áreas, o que provoca um saldo inferior ao arrecadado, tornando assim, incapaz o suprimento das demandas do sistema. (ZUBA, 2011)

\section{PRINCÍPIO DA RESERVA DO POSSÍVEL EM MATÉRIA PREVIDENCIÁRIA}

O princípio da reserva do possível surgiu na Alemanha, notadamente em meados dos anos 70, a partir de uma ação judicial promovida por estudantes que não haviam sido aprovados no curso de medicina em razão da limitação das vagas em cursos superiores em universidade públicas. Os estudantes se basearam no artigo 12 da Lei fundamental da Alemanha, que expressa o direito de que todos os cidadãos alemães possuem em escolher livremente a profissão, local de trabalho e a instituição de formação. Todavia, a corte alemã concluiu que o referido requerimento era vazio de razoabilidade, pois eles só podiam exigir do Estado aquilo que possivelmente ele era capaz de oferecer. Esse entendimento passou a ser conhecido como princípio da reserva do possível, respaldado pelo princípio da razoabilidade da pretensão frente às necessidades da população. (FERNANDO MÂNICA, 2007)

Observa-se que, na sua origem, o princípio da reserva do possível não está diretamente relacionado com recursos financeiros necessários à efetivação dos direitos sociais, mas, sim, a inexistência de razoabilidade para a concretização da pretensão proposta. No Brasil, por outro lado, utiliza-se deste instrumento como eminente recurso de restrição aos serviços essenciais, sedo considerado por muitos autores como "princípio da reserva do 
financeiramente possível”. Krell (2002) critica a deturpação de definição do princípio da reserva do possível. Segundo ela:

\begin{abstract}
Devemos nos lembrar que os integrantes do sistema jurídico alemão não desenvolveram seus posicionamentos para com os direitos sociais num Estado de permanente crise social e milhões de cidadãos socialmente excluídos. Na Alemanha - como nos países centrais - não há um grande contingente de pessoas que não acham vagas nos hospitais mal equipados da rede pública; não há necessidade de organizar a produção e distribuição da alimentação básica a milhões de indivíduos para evitar sua subnutrição ou morte; não há altos números de crianças e jovens fora da escola; não há pessoas que não conseguem sobreviver fisicamente com o montante pecuniário de assistência social que recebem, etc. (KRELL, 2002, p.20)
\end{abstract}

Portanto, em solo pátrio, o princípio da reserva do possível deve ser implementado levando em consideração a realidade social e econômica da população. Assim, é expressamente inconcebível sua previsão frente a concretização dos direitos já positivados constitucionalmente.

Contudo, em virtude de uma hipotética crise econômica, que afetasse diretamente os recursos financeiros do Estado e inviabilizasse a implementação dos direitos sociais, o que geraria um conflito de princípios, como por exemplo, a reserva do possível e a proibição do retrocesso, seria necessária uma ponderação de princípios. Assim, o Estado deveria fazer escolhas, estabelecendo critérios e prioridades a serem adotados. Para Sarlet (2004) o parâmetro de escolha, deveria sempre, ser definido, levando em consideração a inviolabilidade dos direitos garantidores de uma vida digna. Tendo em vista o caso concreto, é imprescindível a observância do princípio da proporcionalidade, assim como explica Severo:

Neste aspecto o princípio da proporcionalidade representa talvez a mais importante ferramenta de que dispõe o judiciário para enfrentar as questões controversas envolvendo a Cláusula da reserva do Possível, o qual deve ser aplicada, sem prejuízo à garantia dos direitos fundamentais, identificando prevalências, interpretações e possibilidades existentes para a solução das lides (SEVERO, 2010. p.41-42)

Nesse entendimento, verifica-se que cabe ao Poder Judiciário aplicar a ponderação guiando-se sempre pela proporcionalidade, certificando-se que efeitos da prevalência de um princípio não cause danos a efetivação dos direitos fundamentais. Para Daniel Sarmento (2000), o aplicador do direito deve ser ainda mais abrangente ao verificar qual princípio deve predominar, pois nenhuma decisão pode ferir com a dignidade da pessoa humana, que é um fundamento para a Constituição Cidadã de 1988. 
Humberto Ávila (2003), referindo-se à ponderação de princípios, bens ou valores, chama atenção para a fundamentação constitucional. Nesse sentido, prepondera estar alicerçado qualquer decisão que dê preferência a um princípio em detrimento de outro, com destaque aos postulados de razoabilidade e proporcionalidade.

O Supremo Tribunal Federal, na verificação da aplicabilidade do princípio da reserva do possível, fez uma concisa advertência ao uso indiscriminado e irresponsável deste instrumento com a mera justificativa de insuficiência orçamentaria. Contudo, não vale dizer que, o princípio não possua eficácia no caso concreto. Antes de proferir decisão, deve haver comprovada incapacidade econômica para um determinado fim. Nas palavras do Ministro Celso de Mello:

Cumpre advertir, desse modo, que a cláusula da "reserva do possível"- ressalvada a ocorrência de justo motivo objetivamente aferível - não pode ser invocada, pelo Estado, com a finalidade de exonerar-se do cumprimento de suas obrigações constitucionais, notadamente quando, dessa conduta governamental negativa, puder resultar nulificação ou, até mesmo, aniquilação dos direitos constitucionais impregnados de um sentido de essencial fundamentalidade. (MELLO, STF, 2004)

Assim, não basta afirmar que não existem recursos para a concretização de um determinado direito ou prestação de um serviço essencial à sociedade, o que pode ocorrer em virtude de uma profunda crise econômica. Antes de restringir, reduzir ou retroceder algum direito social, deverá ser criteriosamente comprovada a chamada "exaustão orçamentária", caso contrário, poderá ser alvo de ação de inconstitucionalidade.

As crises econômicas e o princípio da reserva do possível podem conceder margens para modificação de normas com alegação de escassez de capital. As reformas são, muitas vezes, o meio mais seguro que o poder infraconstitucional recorre para adequar a legislação de acordo com o contexto social e econômico do país. Assim ocorreu com o sistema de previdência social do Brasil, que passou por uma reformulação em suas normas, mediante a emenda constitucional $n^{\circ} 103$ de 2019. Referida modificação estabeleceu regras de transição e disposições transitórias para o acesso aos benefícios previdenciários. O principal objetivo da reforma, apontado pelo congresso, foi o déficit nas contas da previdência social.

Embora não tenha sido invocado diretamente, o princípio da reserva do possível se constituiu como um instrumento sustentador da reforma da previdência, já que a manutenção das normas originárias foi considerada insustentáveis do ponto de vista econômico. Mas, 
como supõe a jurisprudência, é insuficiente a alegação de inexistência de recursos financeiros se não for respaldada por aferição concisa.

Sobre esse assunto, é válido analisar o estudo feito por Denise Gentil (2006), intitulado "A política fiscal e a falsa crise na Seguridade Social Brasileira - análise financeira do período 1990-2005”, onde são expostos sólidos argumentos que apontam para uma gestão irresponsável dos recursos da previdência. A partir de informações obtidas por meio de relatórios de execução orçamentária emitidos pelo SIAFI (Sistema Integrado de Administração Financeira do Governo Federal) e dados retirados nos sites do extinto Ministério da Previdência, Ministério da Fazenda, Ministério do Planejamento e Banco Central, Gentil (2006), pode concluir que o sistema de seguridade social, que engloba a previdência, é financeiramente sustentável. Contudo, parte desses recursos são desvinculados para suprir outras demandas, principalmente o pagamento de juros de amortização das dívidas da união, assim como outras despesas correntes do orçamento fiscal.

A desvinculação dos recursos públicos é um dispositivo legal que autoriza a retirada de uma parte das receitas, das taxas e das contribuições sociais para gastos não originariamente previstos. Esse desvio é chamado de DRU (Desvinculação dos Recursos da União) e é definido por Emenda Constitucional.

A primeira emenda definidora da DRU foi criada em 1994, como tempo de vigência estabelecido em dois anos. Contudo, essa previsão foi sendo mantida ao longo dos anos, mediante prorrogação da emenda originária e criação de novas. Atualmente, a DRU, é regida pela Emenda Constitucional $\mathrm{n}^{\circ} 93$ de 2016, válida até o final de 2023, que trouxe uma modificação em relação as anteriores, a saber, o aumento da porcentagem permitida para desvinculação de $20 \%$ para $30 \%$.

$\mathrm{Na}$ pesquisa de Gentil (2006), foi percebido que a desvinculação da receita da seguridade social excedia o permitido, que na época era $20 \%$, e os números que eram utilizados para avaliar a situação financeira da previdência era o resultado da desvinculação dos recursos. A autora chama atenção também para a base de financiamento da seguridade social, que é ampla e não se restringe apenas as contribuições ao INSS (Instituto Nacional do Seguro Social), como normalmente é proferido nos discursos pró reforma, mas também ao arrecadamento via COFINS e CSLL. Gentil (2006) cita também a CPMF, mas essa 
contribuição foi extinta em 2007, por consequência, deixou de fazer parte da fonte de custeio da seguridade social.

Ainda que pareça antigo e desatualizado, o resultado pesquisa de Denise Gentil (2006) ainda é confirmado nos estudos mais recentes acerca da situação financeira do sistema previdenciário brasileiro. A título de exemplo, pode-se destacar o resultado da Comissão Parlamentar de Inquérito (CPI) da Previdência, em 2017, que teve como relator o senador Hélio José (PROSDF). O principal objetivo da CPI foi verificar a situação financeira do sistema e até que ponto a reforma era realmente necessária.

O resultado da CPI foi um relatório de 253 (duzentas e cinquenta e três) páginas, o qual salienta que, ao contrário do que se vincula na imprensa e nos meios oficiais do governo, não existe déficit da previdência, mas, sim, má gestão dos recursos, já que, de acordo com a investigação, o maior e mais grave problema da Previdência Social advém da vulnerabilidade e da fragilidade das fontes de custeio do sistema de seguridade social. (BRASIL, 2017. $\mathrm{P}, 192)$.

Ao final do documento, o relator sugere dois projetos de lei e três Proposta de Emenda à Constituição. Uma das PECs sugeridas, era a proibição da Desvinculação das Receitas da União (DRU) na área da seguridade social (BRASIL, 2017).

De acordo com Zuba (2011), para resolver o impasse e as contradições atinentes ao estado financeiro da previdência, seria necessário um controle maior do poder público e da sociedade sobre o "caixa, a arrecadação, a administração das verbas e de todo sistema previdenciário" (2011, p.129). Isto porque, na sua concepção, o que existe é uma apropriação indébita das contribuições da previdência, por parte do Estado, o que provoca um desequilíbrio nas finanças do sistema.

No entanto, a CPI da Previdência não foi suficientemente capaz de conter as modificações do sistema previdenciário. Isto por que, dois anos após a conclusão do relatório, a Emenda Constitucional $\mathrm{n}^{\circ}$. 103, foi aprovada no Congresso Nacional e entrou em vigência em 2019, modificando normas constitucionais dos Regimes de Previdência Social. Diante deste contexto, considera-se importante a análise das principais mudanças normativas e os impactos que elas podem gerar sob a vida da população brasileira. 


\section{A EMENDA CONSTITUCIONAL $\mathrm{N}^{\circ} 103$ DE 2019 E AS MODIFICAÇÕES DO SISTEMA DE PREVIDÊNCIA SOCIAL.}

Antes de abordar diretamente as mudanças provocadas pela emenda, faz-se uma breve análise sobre a seguridade social, especificamente o direito à previdência na legislação brasileira.

O sistema de seguridade está amparado na constituição pelo artigo 193 e 194, integrada na Ordem Social e regido pelos primados do trabalho e da justiça social. A seguridade Social, então, é o conjunto integrado de ações de iniciativa dos Poderes Públicos e da sociedade, que são destinadas a garantir os direitos à previdência social, a saúde e a assistência social. Segundo Corrêa (1999. P, 67) "pela definição constitucional já é possível notar que a Seguridade Social é gênero, da qual são espécies a Saúde, a Previdência e a Assistência Social”"

Sobre a fonte de financiamento, a Seguridade Social será financiada por toda a sociedade, de forma direta por meio das contribuições sociais devidas pela empresa, pelos empregados, pelos trabalhadores, os incidentes sobre os concursos de prognostico e sobre importação de bens ou serviços do exterior. E de forma indireta, pelo governo, com utilização dos recursos da União, Estados, Distrito Federal e Municípios. (BRASIL, 1988) ${ }^{5}$

O Estado, pode ainda, mediante sua função legislativa, instituir lei que consagre mais fontes de custeio para a criação ou manutenção da seguridade social. Contudo, não poderá haver criação, majoração ou expansão de benefício ou serviço da seguridade social sem a correspondente fonte de custeio, norma esta prescrita constitucionalmente.

A tríade que forma a seguridade social possui princípios e objetivos distintos entre si. O primeiro âmbito é a Saúde, que, conforme o artigo 196 da Constituição Federal, é destinada a todos e é dever do Estado, tendo que ser garantida por meio de políticas sociais e econômicas, com objetivo à redução dos casos de doenças e outros danos à saúde, conforme expressa a lei 8.080/99. O seu caráter universal garante que todos, sem exceção, tenham

\footnotetext{
${ }^{5}$ Do orçamento fiscal da união, Zuba (2016) lembra dos diversos fundos existentes, tais como o fundo de Previdência e Assistência Social, Fundo Nacional de Saúde; fundo Nacional de Assistência Social; Fundo de Erradicação da Pobreza e Fundo de Amparo ao Trabalhador, que são importantes recursos para as ações da Seguridade Social.
} 
direito aos serviços de saúde, inclusive àqueles que possuam renda suficiente para arcar com planos privados.

O segundo âmbito da Seguridade Social é a Assistência Social, que se caracteriza por um serviço de caráter restritivo. Ou seja, diferentemente da Saúde, é destinada para um grupo específico de pessoas: aqueles que dela necessitam. Em outras palavras, apenas quem não tem condições para manter seu próprio sustento pode ser beneficiado pela assistência, que agindo "Por meio de atividade particulares e estatais, visando à concessão de pequenos benefícios e serviços independentemente de contribuição do próprio interessado". (MARTINS, 2011, P.484) A Assistência Social está prevista nos artigos 203 e 204 da constituição brasileira e na legislação ordinária pela Lei Orgânica da Assistência Social (LOAS) nº 8742/93.

Já o terceiro âmbito desta mencionada tríade é a Previdência Social, foco deste estudo. Trata-se de um sistema de contribuição e de filiação obrigatória, que visa proteger seus segurados, e os dependentes desse, das eventualidades que impossibilitem para o exercício do trabalho. Pode-se mencionar como exemplo, os casos de doença, invalidez, morte, idade avançada, maternidade e desemprego involuntário.

O Brasil adota dois tipos de regimes públicos de previdência social, o Regime Próprio (RPPS) e o Regime Geral (RGPS). Ambos são de caráter contributivo e de filiação obrigatória. A legislação prevê ainda o regime privado de previdência, caracterizado por sua natureza facultativa e complementar. Todos os regimes são submetidos aos princípios da Seguridade social expresso no artigo 194 da constituição brasileira, além de obedecerem às legislações sociais que demarcam os objetivos da justiça social. (BALERA, 2006).

O Regime Geral de Previdência Social é organizado pelo Instituto Nacional do Seguro Social (INSS) e pela Receita Federal do Brasil, tem finalidade de proteger seus segurados, bem como seus dependentes dos infortúnios descritos pela constituição federal. Qualquer pessoa que exerça atividade remunerada é compulsoriamente inserida no RGPS, salvo os que cumprirem exigências de inserção ao RPPS.

São segurados obrigatórios do Regime Geral de Previdência: os trabalhadores que mantém vínculo empregatício regido pela Consolidação das Leis do Trabalho (CLT); os trabalhadores domésticos; os trabalhadores avulsos, aquele que presta serviço a diversas empresas, sem vínculo empregatício, de caráter urbano ou rural definido pelo regulamento (lei 
8213/91); o contribuinte individual, que engloba os donos de empresas e os autônomos; e os trabalhadores rurais que trabalham sob regime de economia familiar.

O Regime Geral de Previdência Social ainda aceita os contribuintes facultativos, que mesmo sem exercer trabalho remunerado queira contribuir para a previdência social. Isto porque obedece ao princípio da universalidade da cobertura e do atendimento.

Instituído pelo artigo 40 da Constituição federal, o Regime Próprio de Previdência Social é destinado aos servidores públicos titulares de cargo efetivo da União, Estados, Municípios e Distrito Federal. É intitulado Regime Próprio, pois cada ente da federação pode ter o seu, cujo objetivo é organizar a previdência tanto dos servidores públicos em exercício como dos aposentados e pensionistas desse regime. (BRIGET, 2007)

A Previdência Social oferece quatro espécies de benefícios aos seus segurados, são eles: as aposentadorias, os auxílios, os salários e a pensão por morte, além de prestar os serviços de reabilitação profissional, perícia médica e serviço social. Ambos benefícios e serviços estão descritos e regulamentados pela lei $\mathrm{n}^{\circ}$ 8.213/91, referente ao plano de Benefício Previdenciário.

O Direito Previdenciário tem como fonte material a Lei Orgânica da Seguridade Social, $\mathrm{n}^{\circ} 8.212 / 91$; a lei 8.213/91, que dispõe sobre os benefícios da previdência; o decreto 3048/99, que regulamenta a previdência social, bem como pela Constituição Federal de 1988. Todos esses dispositivos legais foram, em certa medida, afetados por trechos e adaptações das novas regras constitucionais definidas pela emenda constitucional $n^{\circ} 103 / 19$.

A reforma da previdência não afeta o direito adquirido. Ou seja, aquelas pessoas que alcançaram os requisitos até o dia 12 de novembro de 2019 para concessão de algum benefício previdenciário, seguiram as regras antigas.

A atualização supramencionada estabelece ainda regras transitórias, ou seja, aquelas pessoas que já estavam contribuindo para previdência antes da aprovação da Emenda Constitucional $n^{\circ} 103 / 2019$, quando requererem a aposentadoria, as normas de concessão serão disposições transitórias, que atenuam as regras para liberação de benefícios.

As regras de transição, assim como o nome pressupõe, têm como objetivo "efetuar a transição das situações jurídicas consolidadas sob a égide do regime antigo para a vigência do 
novo regime, sem a violação de garantias individuais" (MEDINA, 2020, p. 4). Mas, seguindo o propósito desse estudo, destaca-se aqui as normas permanentes, que afetarão os segurados que adentraram ao sistema a partir da promulgação da Emenda Constitucional n 103/19.

Das regras permanentes a mudança mais expressiva é o fim da aposentadoria por tempo de contribuição no RGPS. A redação da Constituição Federal, anterior a Reforma, garantia a aposentadoria se o contribuinte cumprisse ao menos uma dessas exigências: tempo mínimo de 35 anos de contribuição, se homens e 30 anos, se mulheres; ou idade mínima de 60 anos, se mulher e 65 anos, se homem, com 15 anos de carência para ambos. A nova Emenda Constitucional exige agora cumulativamente a idade mínima de 65 anos para homens e 62 anos para mulheres, e tempo de contribuição de no mínimo 20 anos para os homens e 15 anos de contribuição para as mulheres. Ou seja, as pessoas deverão permanecer por mais tempo trabalhando para exercer seu direito à aposentadoria, que agora exige tanto uma idade mínima como um tempo de contribuição definido.

Pelas normas vigentes até 13 de novembro de 2019, era concedido ao segurado 4 espécies de aposentadorias, eram elas: aposentadoria por invalidez, aposentadoria por tempo de contribuição, aposentadoria por idade e aposentadoria especial. Acontece que, a aposentadoria devida aos que cumpriram tempo de contribuição exigido, foi extinta, sendo incorporada algumas de suas regras à aposentadoria por idade.

A aposentadoria especial também foi em grande parte modificada pela emenda $n^{\circ}$ 103/19. Essa espécie de aposentadoria é devida aos segurados que exercem atividades sob condições especiais que prejudiquem a saúde ou integridade física. Nessas condições, a concessão de aposentadoria segue regras e critérios diferenciados da regra geral.

A legislação assegurava tempo de contribuição de 15, 20 e 25 anos para esse tipo de trabalhador, sendo definido de acordo com a grau de exposição ao agente nocivo à saúde. Pela regra antiga, declarado e comprovado trabalho nessas situações, com tempo de contribuição mínimo, o segurado poderia se aposentar a qualquer tempo, independente de idade. Mas, com a reforma, o cenário para o segurado especial mudou, de acordo com o artigo 19 da emenda constitucional $n^{\circ} 103 / 19$, além do tempo de contribuição será requerido uma idade mínima. ${ }^{6} \mathrm{~A}$

\footnotetext{
${ }^{6}$ a) 55 (cinquenta e cinco) anos de idade, quando se tratar de atividade especial de 15 (quinze) anos de
} contribuição; b) 58 (cinquenta e oito) anos de idade, quando se tratar de atividade especial de 20 (vinte) anos de 
referida norma se aplica tanto para os homens como para as mulheres, não havendo diferenciação de idade quanto ao sexo.

A aposentadoria especial cumpre um papel de compensação aos trabalhadores que estão inseridos em atividades que ponha em risco a sua saúde. A particularidade desse de aposentadoria jaz em retirar o trabalhador precocemente de suas atividades laborais, a fim de diminuir a sua exposição aos agentes físicos, químicos ou a associação deles. Contudo, percebe-se que a proteção aos segurados especiais foi fortemente afetada pela reforma, já que o trabalhador, além de cumprir o tempo de contribuição exigido, ainda terá que completar uma idade estipulada, fazendo com que os trabalhadores permaneçam por mais tempo no ambiente possivelmente degradante à sua saúde.

O Departamento Intersindical de Estatísticas Socioeconômicas (DIIESE), chama atenção para o fato de a definição de uma idade mínima para todas as aposentadorias do regime geral provocará um quadro de desproteção aos trabalhadores em idade avançada que estiverem fora do mercado de trabalho. Isto por que podem encontrar dificuldade de se manterem empregados nessa idade, caracterizando uma verdadeira violação aos princípios da Seguridade Social (DIEESE, 2017).

As mudanças não foram apenas nas regras de concessão das aposentadorias, mas também no cálculo dos benefícios. Antes da promulgação da reforma da previdência, o cálculo de qualquer aposentadoria era feito a partir da média simples dos $80 \%$ maiores salários de contribuição a partir de julho de 1994 (ou desde a primeira contribuição, se for posterior a julho de 1994), correspondente a $100 \%$.

Com a reforma, a porcentagem caiu para $60 \%$ da média de todos os salários de contribuição. No que concerne a aposentadoria por idade, ainda que o segurado cumpra a idade mínima e o tempo de contribuição, a renda inicial da aposentadoria por idade será de $60 \%$ da média dos salários de contribuição. Com as novas normas, se o trabalhador, quando alcançados os requisitos idade e tempo de contribuição, quiser se aposentar, ele receberá um valor $40 \%$ menor que ele receberia se ainda valessem as regras antigas.

contribuição; ou c) 60 (sessenta) anos de idade, quando se tratar de atividade especial de 25 (vinte e cinco) anos de contribuição (BRASIL, 2019) 
Contudo, o empregador tem a opção de continuar trabalhando para que o valor de sua aposentadoria aumente, pois, a Emenda estabelece um acréscimo de $2 \%$ para cada ano de contribuição que exceder o tempo de contribuição exigido. Dessa forma, para que o trabalhador receba os $100 \%$ da média dos salários de contribuição, ele terá que contribuir por 35 anos se for mulher e 40 se homem. Podendo ainda exceder os $100 \%$, caso continue contribuindo.

A regra do acréscimo de $2 \%$ também se aplica aos trabalhadores em condições especiais, contudo há uma ressalva que diferencia homens e mulheres, a saber: o homem que tem direito a aposentadoria especial que determine 15, 20 ou 25 anos de contribuição só será acrescido 2\% para cada ano que supere os 20 anos (Mesmo naquela atividade que exige um tempo mínimo de 25 anos, os $2 \%$ será computado a partir do primeiro ano que superar os 20 de efetivo exercício de trabalho); para as mulheres, para aposentadoria que determine 15, 20 e 25 anos, serão acrescidos $2 \%$ para cada ano que supere os 15 anos de contribuição.

Portanto, verifica-se a intenção da reforma em diminuir o valor da aposentadoria e aumentar o tempo de contribuição, compelindo o indivíduo a trabalhar por mais tempo, para receber o valor integral de sua aposentadoria. A Reforma afetou não apenas as aposentadorias, mas modificou também regras de concessão e de cálculo da pensão por morte, um benefício devido aos dependentes do segurado que faleceu, aposentado ou contribuinte da previdência social.

Até o dia 12 de novembro de 2019, os dependentes tinham direito a $100 \%$ da renda mensal da aposentadoria que o segurado recebia ou daquela que teria direito se estivesse aposentado por invalidez na data de seu falecimento, divididos em partes iguais entre os dependentes. Hoje, com a nova legislação, esse percentual caiu para $60 \%$, que se refere aos $50 \%$ da pensão mais $10 \%$ por dependente. No caso, se houver mais de um dependente, a cálculo é o mesmo, divide $50 \%$ para a quantidade de dependentes e acrescenta $10 \%$ para cada dependente. $\mathrm{O}$ adicional de $2 \%$ será calculado para cada ano que o segurado ultrapassou 20 anos de contribuição.

Os efeitos da redução do valor da pensão por morte já são visíveis em menos de um ano da reforma da previdência, aponta uma matéria do site UOL (2020). Com as mortes provocadas pela pandemia do Coronavírus no Brasil, muitas pessoas passam por um duplo dilema: a perda de um ente querido e a renda familiar diminuída pela não integralidade da 
pensão por morte, já que, só são beneficiários dos $100 \%$ da média dos salários de contribuição, os dependentes do segurado vítima de acidente de trabalho.

Outro fator destacado pela matéria, é a redução da pensão por morte quando acumulada com aposentadoria, pois o valor total dos benefícios acumulados sofre redução, mudança pautada pela emenda $n^{\circ} 103 / 19$.

No que concerne a acumulação de benefícios, o direito previdenciário brasileiro permite o recebimento conjunto de benefícios, quando for concedido, um na qualidade de segurado e o outro na condição de dependente, como é o caso da aposentadoria e a pensão por morte; ou ainda, duas pensões que tenham origem de regimes distintos.

Até a promulgação da reforma, era possível receber a integralidade do valor da acumulação dos benefícios, nos requisitos supracitados. Mas, a partir das normas da reforma da previdência, a integralidade dos valores não será possível quando um dos benefícios ultrapassar o valor de um salário mínimo, pois haverá a aplicação de um redutor no valor do benefício menos vantajoso.

Na hipótese de acúmulo de dois benefícios, é assegurada a percepção do valor integral do benefício mais vantajoso e de uma parte de cada um dos demais benefícios, assim como define no $\$ 2$ do artigo 24 da emenda $n^{\circ} 103 / 19^{7}$. A acumulação dos benefícios ainda é reconhecida pela nova lei, mas o benefício menos vantajoso será reduzido proporcionalmente ao seu valor, caso seja maior que um salário mínimo. Essa mudança afeta principalmente os idosos, que tendem a acumular a pensão por morte do cônjuge e sua aposentadoria, nesse contexto a acumulação tem como principal objetivo manter a mesma situação financeira que a família tinha antes do falecimento do segurado.

Esses foram alguns destaques elencados, a fim de haver uma análise das mudanças normativas em face do princípio da proibição ao retrocesso.

\section{CONSIDERAÇÕES FINAIS}

\footnotetext{
${ }^{7}$ I - 60\% (sessenta por cento) do valor que exceder 1 (um) salário-mínimo, até o limite de 2 (dois) saláriosmínimos; II - 40\% (quarenta por cento) do valor que exceder 2 (dois) salários-mínimos, até o limite de 3 (três) salários-mínimos; III - 20\% (vinte por cento) do valor que exceder 3 (três) salários-mínimos, até o limite de 4 (quatro) salários-mínimos; e IV - 10\% (dez por cento) do valor que exceder 4 (quatro) salários-mínimos. (BRASIL, 2019)
} 
O Princípio da Proibição ao Retrocesso é um mandado de otimização que atua como bloqueio das ingerências do Estado, impedindo que haja atraso nas conquistas na área social. A ordem jurídica do Brasil reconhece também a aplicabilidade do princípio da reserva do possível, que tem como fundamento a proporcionalidade e a razoabilidade da pretensão deduzida, mas impõe exigências para sua validação frente a supressão de direitos consagrados na legislação.

Esses princípios divergem quando se pesquisa acerca da prestação positiva do Estado. No âmbito do direito à previdência, as modificações normativas não podem ser justificadas unicamente por falta de recursos. Antes, porém, deve haver comprovação incontestável da incapacidade econômica do setor governamental para prestação dos benefícios.

A reforma da previdência foi aprovada com a justificativa de um grande saldo negativo nos caixas da previdência. Contudo, como apontam alguns estudos, e, até mesmo, a CPI da previdência, realizada para verificar a real necessidade da reforma, o que existe é uma má gestão dos recursos da previdência social, concluindo que não há propriamente um déficit, mas sim, a desvinculação, além do permitido, das receitas do sistema previdenciário.

Em análise à metamorfose das principais normas de concessão e de cálculo dos benefícios provocada pela reforma da previdência, por seu caráter flagrantemente retrocessivo e restritivo dos direitos já conquistados pela sociedade, colidem com o princípio da vedação ao retrocesso social. Constata-se que o principal propósito da emenda $\mathrm{n}^{\circ}$ 103/19 foi legalizar a exploração do trabalhador, fazendo com que ele trabalhe por muito mais tempo e receba um valor reduzido de seu benefício.

Não poderia o Congresso Nacional ter votado favoravelmente a essa reforma, com a única justificativa o rombo nas contas da previdência, sendo desconsiderado os vários estudos que apontavam como grande o causador dos desequilíbrios financeiros a Desvinculação dos Recursos da União na arrecadação das contribuições sociais.

Portanto, o princípio da vedação ao retrocesso não foi respeitado na formulação das novas normas previdência. Os efeitos, mesmo que pequenos, já começam a ser percebidos em menos de um ano de sua promulgação. 


\section{REFERÊNCIAS}

ANDRADE, Gabriela Colhado. O direito fundamental a previdência. Rev. Âmbito jurídico. 2020. Acesso em: 1 de set. 2020. Disponível:

https://ambitojuridico.com.br/cadernos/direito-previdenciario/o-direito-fundamentalaprevidencia-social-e-a-proibicao-de-retrocesso/\#_ftn1

ÁVILA, Humberto. Limites à tributação com base na solidariedade social. In: GRECO, M. A.; GODOI, M. S. de (Coords.). Solidariedade social e tributação. São Paulo: Dialética, 2005. p. $68-88$.

BRASIL. Constituição (1988). Constituição da República Federativa do Brasil. Disponível em: http://www.planalto.gov.br/ccivil_03/Constituicao/Constituicao.htm. Acesso em: 20 agos. 2020.

BRASIL. LEI 8.213 de 24/07/1991 - Dispõe sobre os Planos de Benefícios da Previdência Social e dá outras providências. Disponível em http://www.planalto.gov.br. Acesso em: 12 set. 2020 .

BRASIL. Lei no 8.213, de 24 de julho de 1991. Dispõe sobre os Planos de Benefícios da Previdência Social e dá outras providências. Disponível em:

<http://www.planalto.gov.br/ccivil_03/Leis/L8213cons.htm> Acesso em 03 de set. 2020.

BRASIL. Decreto no 3.048, de 06 de maio de 1999. Aprova o Regulamento da Previdência Social, e dá outras providências. Disponível em:

<http://www.planalto.gov.br/ccivil/decreto/D3048.htm> Acesso em: 05 de set. 2020.

BRASIL. Emenda Constitucional No 103, de 12 de novembro de 2019. Altera o sistema de previdência social e estabelece regras de transição e disposições transitórias. Disponível em: <http://www.planalto.gov.br/ccivil_03/constituicao/emendas/emc/emc103.htm>. Acesso em: 13 set. 2020.

BRASIL. Senado Federal. Comissão Parlamentar de Inquérito do Senado Federal destinada a investigar a contabilidade da previdência social, esclarecendo com precisão as receitas e despesas do sistema, bem como todos os desvios de recursos (CPIPREV): Relatório final. 2017.

BRIGET, Rosalia; VICTORINO, Maria Cristina; HORVATH, Miguel, Previdência Socia: aspectos práticos e doutrinários dos regimes jurídicos próprios. São Paulo: Atlas, 2007.

CANOTILHO, José Joaquim Gomes. Direito Constitucional e teoria da constituição. $7^{\text {a }}$ edição. Coimbra: Editora Almedina, 2003.

CORRÊA, Wilson leite. Seguridade e Previdência Social na Constituição de 1988. Jus

Navigandi, Teresina, ano 3, n. 34, ago. 1999.

GENTIL, Denise L. A Política Fiscal e a Falsa Crise da Seguridade Social Brasileira Análise financeira do período 1990-2005. Tese (Doutorado em Economia) - Instituto de Economia da Universidade Federal do Rio de Janeiro, Rio de Janeiro, 2006 
KRELL, Andreas J. Direitos Sociais e Controle Judicial no Brasil e na Alemanha: os descaminhos de um direito constitucional "comparado". Porto Alegre: Sergio Antônio Fabris Editor, 2002. p. 20.

MÂNICA, Fernando Borges. Teoria da Reserva do Possível: Direitos Fundamentais a Prestações e a Intervenção do Poder Judiciário na Implementação de Políticas Públicas. Revista Brasileira de Direito Público, Belo Horizonte, ano 5, n. 18, p. 169 186, jul./set. 2007

MARTINS, Sergio Pinto. Direito a seguridade social. 31 ed. São Paulo: Atlas, 2011.

MEDINA, Damares. Regras de transição em matéria previdenciária. Revista Jus Navigandi, ISSN 1518-4862, Teresina, ano 19, n. 4006, 20 jun. 2014. Disponível

em: https://jus.com.br/artigos/29171. Acesso em: 5 out. 2020

MELLO, Celso Antônio Bandeira de. Curso de Direito Administrativo. 15 ed. São Paulo: Malheiros, 2003, p.113.

NETTO, Sérgio de Oliveira. O princípio da reserva do possível e a eficácia das decisões judiciais. In Revista da AGU n. 7, Brasília: 2005, p.147

SACAMOTO, Leonardo. Reforma da Previdência cortou pensões e impacta viúvos e órfãos da covid-19. UOL. Disponível em:

https://noticias.uol.com.br/colunas/leonardosakamoto/2020/09/26/pensao-a-viuvos-e-orfaosda-covid-e-menor-devido-a-reforma-daprevidencia.htm?cmpid=copiaecola. Acesso em: $01 \mathrm{de}$ out. de 2020

SARLET, Ingo Wolfgang. A eficácia dos direitos fundamentais. 2 ed. Porto Alegre: Livraria do Advogado, 2001.

SARLET, Ingo Wolfgang. A eficácia do direito fundamental à seguraça jurídica: dignidade da pessoa humana, direitos fundamentais e proibição de retrocesso social no direito constitucional brasileiro. Revista Direito Social. Porto alegre: totadez, n. 4, 2004.

SARLET, Ingo Wolfgang. A assim designada proibição de retrocesso social e a construção de um direito constitucional comum latinoamericano. Revista Brasileira de Estudos Constitucionais - RBEC. Belo Horizonte, ano 3, n. 11, jul./set. 2009.

SARLET, Ingo Wolfgang. Proteção dos direitos fundamentais diante das emendas constitucionais (parte 2). Revista Consultor Jurídico. São Paulo. 20 de maio de 2016. Disponível em: https://www.conjur.com.br/2016-mai-20/direitos-fundamentaisprotecaodireitos-fundamentais-diante-emendas-parte. Acesso em: 04 agost. 2020

SARLET, Ingo Wolfgang. A eficácia do direito fundamental à seguraça jurídica: dignidade da pessoa humana, direitos fundamentais e proibição de retrocesso social no direito constitucional brasileiro. Revista Direito Social. Porto alegre: totadez, n. 4, 2004.

SARMENTO, Daniel. A ponderação de Interesses no Constituição Federal. Rio de Janeiro: Lumen luris, 2000.

SEVERO, Renata Corrêa. O princípio da Reserva do Possível e eficácia das decisões judiciais em face da administração Pública. Revista Fórum Administrativo - Direito Público FA. Belo Horizonte: ano 10, n.112, jun. 2010 
Relatório da CPI da Previdência nega déficit e aponta má gestão. O globo. Brasília. 23 de outubro de 2017. Disponível em:

https://valor.globo.com/politica/noticia/2017/10/23/relatorio-da-cpi-da-previdencianegadeficit-e-aponta-ma-gestao-1.ghtml. Acesso em: 20 de agost. de 2020

VIEIRA JR., Dicesar Beches. Teoria dos direitos fundamentais: evolução

históricopositiva, regras e princípios. Revista da Faculdade de Direito-RFD-UERJ, Rio de Janeiro, 2015, p. 93-9

ZUBA, Thais Maria Riedel de Resende. O direito à seguridade social na Constituição de 1988 e o princípio da vedação do retrocesso. 2011. 150 f. Dissertação (Mestrado em Direito) - Pontifícia Universidade Católica de São Paulo, São Paulo, 2011. 